\title{
Internet of Things (IoT) Sistem Peringatan Dini Bahaya Kebakaran berbasis Android dan Arduino
}

\author{
Nofiandri Setyasmara ${ }^{a}$ \\ ${ }^{a}$ Politeknik Negeri Media Kreatif, Jl Srengseng Sawah Jagakarsa Jakarta Selatan
}

\section{INFORMASI ARTIKEL}

Sejarah Artikel:

Diterima Redaksi: 10 November 2021

Revisi Akhir: 2 Desember 2021

Diterbitkan Online: 3 Desember 2021

\section{KATA KUNCI}

Internet of Things (IoT), Sistem Peringatan

Dini, Bahaya Kebakaran, Android, Arduino

KORESPONDENSI

Email: nofiandri@polimedia.ac.id

\section{A B S T R A C T}

Perkembangan teknologi informasi dan komunikasi (TIK) dewasa ini semakin pesat, internet tidak lagi didominasi oleh penggunaan secara langsung oleh manusia melainkan juga digunakan sebagai sarana "berkomunikasi" antar benda (things) sehingga muncul istilah internet of things (IoT). Sistem peringatan dini bahaya kebakaran yang dibuat di dalam penelitian ini terdiri dari 3 (tiga) sub sistem yaitu yang pertama adalah integrasi perangkat keras sistem mikrokontroler Arduino Uno R3 ATmega328, modul sensor api KY-026, sensor suhu dan kelembaban DHT11, serta modul Ethernet W5100. Sub sistem yang kedua adalah database server menggunakan MySQL. Sub sistem yang ketiga adalah aplikasi perangkat mobile Android yang dibuat menggunakan MIT App Inventor.

Proses pengujian sistem peringatan dini bahaya kebakaran ini dibagi menjadi 3 (tiga) tahap yaitu yang pertama adalah pengujian terhadap integrasi perangkat keras Arduino. Hasil pengujian didapatkan bahwa sensor dapat mendeteksi adanya api ketika api tersebut berada dalam jarak radius lebih kurang 2 meter. Tahap kedua adalah pengujian terhadap kemampuan database server menyimpan data. Hasil pengujian didapatkan bahwa tabel database ter-update per 10 detik sesuai dengan program yang dibuat pada sketsa Arduino. Tahap ketiga adalah pengujian terhadap kemampuan aplikasi Android menampilkan data. Hasil pengujian didapatkan bahwa data pada tampilan aplikasi ter-update per 10 detik sesuai dengan program yang dibuat menggunakan MIT App Inventor.

\section{DOI: https://doi.org/10.46961/jommit.v5i2}

\section{PENDAHULUAN}

Perkembangan teknologi informasi dan komunikasi (TIK) dewasa ini telah merubah cara masyarakat dalam menjalani kehidupan sehari-hari khususnya berkaitan dengan aktivitas mencari informasi dan berkomunikasi. Seluruh lapisan masyarakat saat ini semakin banyak yang memanfaatkan teknologi internet dalam menunjang aktivitasnya sehari-hari.

Sejalan dengan perkembangan teknologi informasi dan komunikasi (TIK) yang semakin pesat, internet tidak lagi didominasi oleh penggunaan secara langsung oleh manusia 008 melainkan juga digunakan sebagai sarana "berkomunikasi" antar benda (things) sehingga muncul istilah internet of things (IoT). Pertumbuhan jumlah perangkat IoT meningkat secara tajam dalam empat tahun belakangan ini. Jumlah perangkat IoT yang aktif di tahun 2018 ini diprediksi lebih banyak dari perangkat mobile (smartphones dan tablets) (Rajkumar, 2016).

Beberapa penelitian terdahulu yang mengimplementasikan konsep/teknologi IoT diantaranya adalah Ojaswini Vijay Duragkar dkk. tahun 2016 yang melakukan penelitian untuk membuat model kerja penerapan IoT pada sistem otomasi industri. Raheela Shahzadi dkk. Pada tahun 2016 melakukan penelitian tentang implementasi sistem pakar dalam mengelola https://doi.org/10.46961/jommit.v5i2 
pertanian menggunakan konsep IoT. R. N. Kulkarni dkk. pada tahun 2017 melakukan penelitian implementasi IoT untuk membuat sistem pengontrol peralatan rumah tangga seperti lampu, kipas angin, keran air, air panas, AC dan mesin cuci.

Dalam penelitian ini implementasi IoT dikhususkan untuk membuat suatu sistem peringatan dini bahaya kebakaran dimana ketika perangkat IoT yang dipasang di rumah mendeteksi adanya kebakaran maka perangkat tersebut dengan segera dapat memberikan informasi berupa alarm di smartphone pemilik rumah.

\section{TINJAUAN PUSTAKA}

\subsection{Mobile Platform Android}

Android adalah sistem operasi untuk mobile device yang awalnya dikembangkan oleh Android Inc. Perusahaan ini kemudian dibeli oleh Google pada tahun 2005. Android dibuat berdasarkan kernel Linux yang dimodifikasi. Android menyediakan platform terbuka bagi para pengembang untuk menciptakan aplikasi mereka sendiri untuk digunakan oleh bermacam piranti bergerak (Safaat, 2012).

\subsection{MIT App Inventor}

App Inventor adalah sebuah aplikasi web pemrograman visual open source yang digunakan untuk mengembangkan aplikasi mobile berbasis android dengan dukungan fitur drag and drop tool. Untuk mendesain sebuah user interface suatu aplikasi dapat dilakukan dengan menyusun komponen-komponen aplikasi menggunakan aplikasi web GUI builder. Selanjutnya behavior dari komponen-komponen tersebut didefinisikan menggunakan sederetan blok instruksi yang cara menggunakannya seperti puzzle.

App Inventor menggunakan Kawa Language Framework dan Kawa's dialect yang dikembangkan oleh Per Brother. Kedua aplikasi tersebut didistribusikan sebagai bagian dari GNU operating system oleh Free Software Foundation. Kedua aplikasi tersebut dijadikan compiler dan menerjemahkan visual block programming untuk diimplementasikan pada platform android (Wolber, 2011).

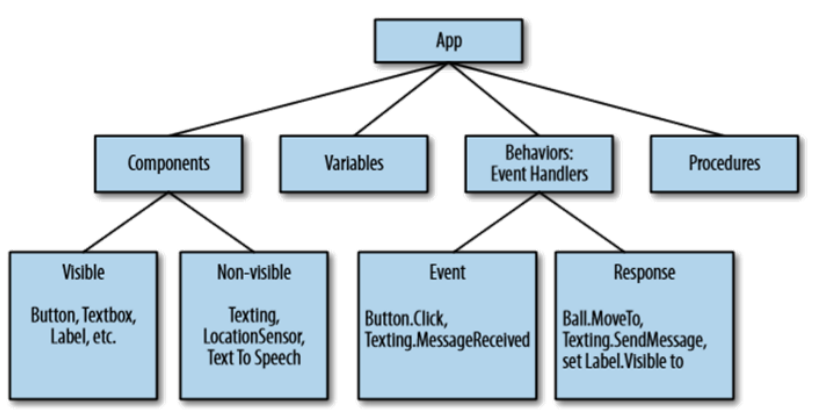

Gambar 1 Arsitektur Aplikasi MIT App Inventor

\subsection{Electronic Prototyping Platform Arduino}

Arduino merupakan platform terbuka bagi pengembangan perangkat elektronika berbasis mikrokontroler. Perangkat keras Arduino terbangun dari sebuah papan mikrokontroler sederhana beserta chipset-nya. Sedangkan pengembangan perangkat lunaknya ditunjang dengan IDE (integrated development environment) berbasis Java. Dimensi perangkat Arduino yang relative kecil serta kemampuannya untuk dapat dikoneksikan melalui jaringan internet menjadi kelebihan untuk berbagai proyek implementasi internet of things (IoT).

Program perangkat lunak bagi perangkat keras Arduino disebut sketsa. Sketsa dibuat di komputer dengan bantuan IDE Arduino. Dengan menggunakan IDE Arduino kode-kode sketsa dapat ditulis, disunting, dan dikonversi menjadi perintah-perintah yang dapat dimengerti oleh perangkat keras Arduino. IDE Arduino juga sekaligus berfungsi untuk mengunggah perintah-perintah tersebut pada papan perangkat keras Arduino.

Perangkat keras Arduino merupakan tempat mengeksekusi perintah-perintah yang ada dalam sebuah sketsa. Perangkat keras Arduino hanya dapat memproses dan mengendalikan dalam besaran listrik dengan demikian dibutuhkan komponen tambahan agar perangkat keras Arduino dapat berinteraksi dengan besaran fisik. Komponen-komponen tersebut dapat berupa sensor yang mengkonversi besaran fisik menjadi besaran listrik ataupun aktuator yang mengkonversi besaran listrik menjadi besaran fisik. Contoh dari sensor antara lain switch, sensor suhu, sensor jarak dan lain-lain. Sedangkan contoh dari aktuator antara lain LED, speaker, motor listrik, dan lain-lain.

Terdapat beberapa macam perangkat keras Arduino original dan berbagai macam perangkat keras Arduino compatible yang dibuat oleh anggota komunitas Arduino yang dapat digunakan menggunakan software Arduino. Perangkat keras Arduino yang paling umum digunakan adalah Arduino Uno sebagaimana yang dapat dilihat pada gambar 2. Arduino Uno memiliki sebuah konektor USB (universal serial bus) yang digunakan untuk menyediakan daya listrik dan juga untuk mengunggah software/sketsa pada papan Arduino.

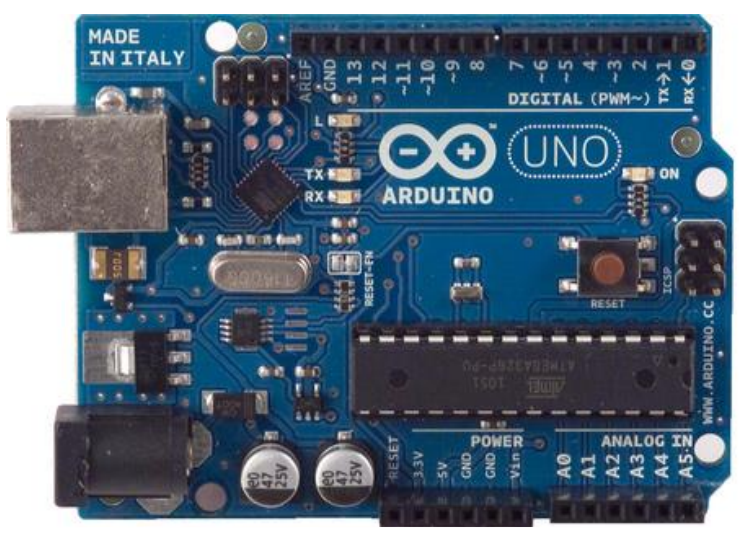

Gambar 2 Perangkat keras Arduino Uno 


\subsection{Research and Development $(R \& D)$}

Penelitian ini bertujuan untuk membuat sebuah purwarupa sistem peringatan dini bahaya kebakaran berbasis teknologi Internet of Things (IoT) menggunakan Android mobile platform dan Arduino electronics prototyping platform. Oleh karena itu, jenis penelitian yang tepat adalah penelitian research and development (R\&D). Menurut Sugiyono (2009), Research and Development (R\&D) adalah metode penelitian yang digunakan untuk menghasilkan produk tertentu dan menguji keefektifan produk tertentu. Produk tersebut dapat dihasilkan dengan menggunakan penelitian yang bersifat analisis terhadap kebutuhan. Pengujian terhadap efektifitas dari produk tesebut dilakukan agar dapat digunakan oleh masyarakat secara luas.

\section{KONSEP PERANCANGAN}

Implementasi Internet of Things (IoT) pada Sistem Peringatan Dini Bahaya Kebakaran Berbasis Android dan Arduino ini diawali dengan perancangan dan perakitan perangkat keras Arduino pendukung sistem. Tahap berikutnya adalah pengembangan perangkat lunak baik perangkat lunak yang akan dibenamkan pada perangkat Arduino dan perangkat lunak yang akan dijalankan pada perangkat Android. Pengembangan perangkat lunak pada penelitian ini mengikuti langkah-langkah baku dalam pembuatan sebuah perangkat lunak (software) antara lain sebagai berikut :

a. System Engineering (rekayasa sistem)

Perangkat lunak merupakan bagian dari sistem yang lebih besar yaitu sistem peringatan dini bahaya kebakaran, maka pekerjaan dimulai dari pengumpulan data agar dapat diketahui elemen- elemen yang hendak dialokasikan ke dalam perangkat lunak. Hal ini penting dilakukan karena perangkat lunak harus berkomunikasi dengan pengguna (manusia), perangkat keras (hardware), dan basis data. Rekayasa sistem menekankan pada pengumpulan kebutuhan fungsional sistem yang akan dibuat.

b. System Analysis (analisis sistem)

Pada tahap ini dilakukan analisa pemecahaan permasalahan dari data dan informasi yang telah didapatkan dari tahap yang sebelumnya, serta mengumpulkan kebutuhankebutuhan apa saja yang harus ada dan terakomodasi pada perangkat lunak yang akan dibenamkan pada perangkat Arduino dan perangkat lunak yang akan dijalankan pada perangkat Android.

c. Design (perancangan sistem)

Ada 4 atribut untuk desain yaitu struktur data, arsitektur sistem, sistem prosedur dan tampilan antar muka. Proses desain mengubah kebutuhan- kebutuhan menjadi bentuk karakteristik yang dimengerti perangkat lunak sebelum dimulai penulisan program. Tahapan ini didokumentasi dengan baik dan menjadi konfigurasi sistem peringatan dini bahaya kebakaran berbasis Android dan Arduino.

d. Coding (pengkodean)

Setelah tahap perancangan sistem (design) kemudian dilanjutkan dengan menerjemahkan desain yang telah dibuat menjadi bentuk yang dapat dimengerti oleh perangkat komputer. Pada tahap ini dilakukan penulisan program menggunakan IDE (integrated development environment)
Arduino untuk membuat perangkat lunak yang akan dibenamkan pada perangkat Arduino. Sedangkan penulisan program untuk membuat perangkat lunak yang akan dijalankan pada perangkat Android menggunakan MIT App Inventor.

e. Testing (pengujian)

Setelah tahap pengkodean program telah dilakukan maka tahap selanjutnya adalah tahap pengujian sistem peringatan dini bahaya kebakaran. Pengujian dilakukan untuk memverivikasi logika internal dari perangkat lunak, fungsi eksternal dari perangkat keras dan mencari segala kemungkinan masalah serta memeriksa apakah sistem peringatan dini bahaya kebakaran berbasis Android dan Arduino yang dibangun tersebut sesuai dengan yang diharapkan.

f. Maintenance (perawatan)

Pada tahap ini dilakukan perawatan terhadap sistem peringatan dini bahaya kebakaran berbasis Android dan Arduino yang sudah jadi. Dalam penggunaannya dimungkinkan akan masih terdapat potensi ditemukannya kesalahan (error) atau ada fitur baru yang perlu ditambahkan, sehingga perlu dilakukan pemeliharaan terhadap sistem yang telah dibangun.

\section{HASIL DAN PEMBAHASAN}

\subsection{Perancangan Sistem}

Diagram blok dari Sistem Peringatan Dini Bahaya Kebakaran Berbasis Android dan Arduino dapat dilihat pada gambar 3. Sistem digolongkan menjadi 3 (tiga) sub sistem yaitu yang pertama adalah integrasi dari perangkat keras sistem mikrokontroler Arduino, modul sensor untuk mendeteksi keberadaan api dan mengukur suhu/kelembaban, dan modul Ethernet untuk memberikan kemampuan Arduino mengirimkan data melalui jaringan internet. Sub sistem kedua adalah server basis data (database server) yang menjadi titik transit data dari perangkat Arduino ke perangkat Android. Sub sistem ketiga adalah aplikasi perangkat mobile Android yang dapat dijalankan pada smartphone ataupun komputer Tablet, sebagai media untuk menampilkan data dan informasi kepada pengguna.

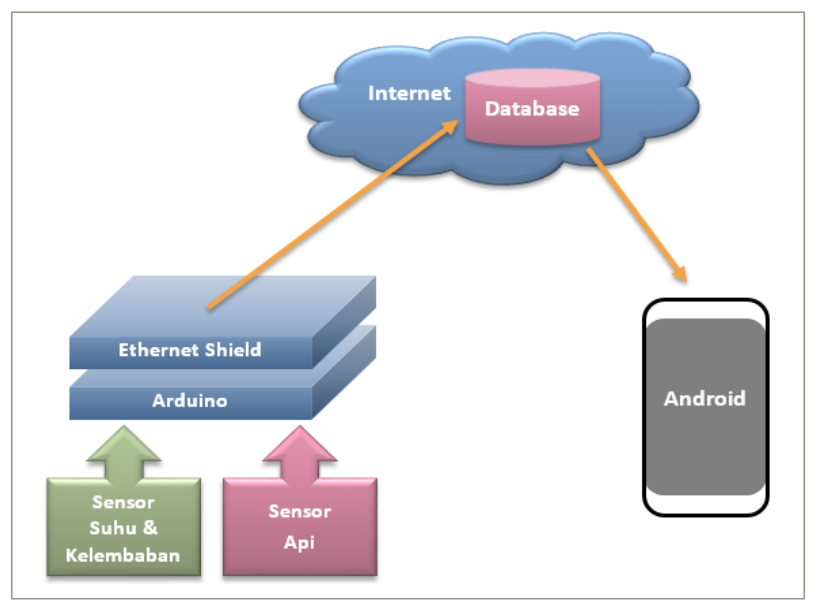

Gambar 3 Diagram Blok Sistem 


\subsection{Perancangan Perangkat Keras (Hardware)}

Hasil perancangan konektivitas antar perangkat keras pada sub sistem yang pertama, yaitu integrasi perangkat Arduino, sensor api, sensor suhu dan kelembaban, serta modul ethernet, berbentuk diagram sirkuit dapat dilihat pada gambar 4. Perangkat keras yang digunakan pada sistem peringatan dini bahaya kebakaran adalah sebagai berikut:

- Mikrokontroler (Arduino Uno R3 ATmega328

ATmega16U2 DIP version)

- Modul Ethernet (W5100 Ethernet Shield HanRun HR11105A)

- Modul Sensor Api (KY-026 Flame Sensor Module)

- Modul Sensor Suhu \& Kelembaban (DHT-11

Temperature \& Humidity Sensor)

- Breadboard (400 titik, ukuran 8,2 x 5,5 x 0,85 cm)

Khusus untuk konektivitas antara modul Ethernet dan board Arduino tidak menggunakan kabel melainkan langsung menggunakan pin male-female yaitu dengan cara diletakkan secara bertumpuk dengan posisi modul Ethernet di atas sedangkan board Arduino berada tepat di bawahnya.

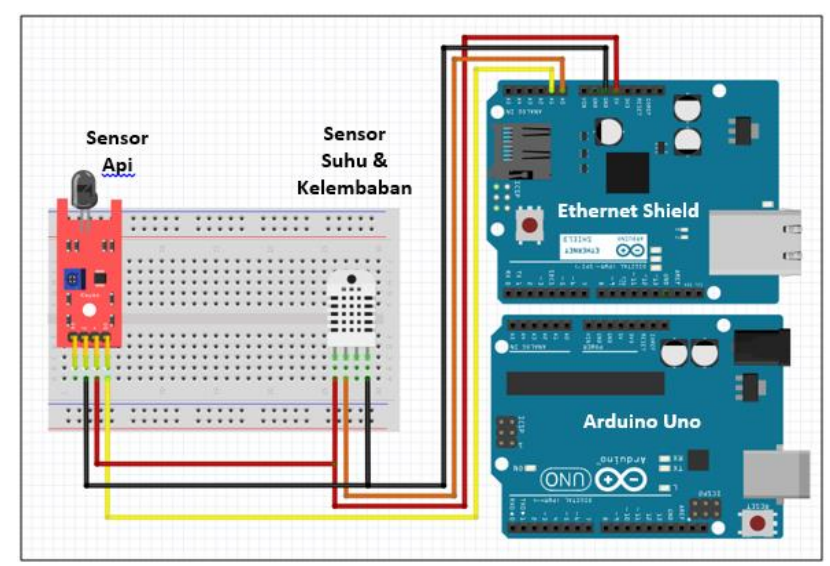

Gambar 4 Diagram Sirkuit Perangkat Keras

Rangkaian perangkat keras yang merupakan integrasi antara board Arduino Uno R3, Ethernet Shield W5100, serta modul sensor api KY-026 dan sensor suhu \& kelembaban DHT-11 yang disusun di atas breadboard 400 titik dapat dilihat pada gambar 5 .

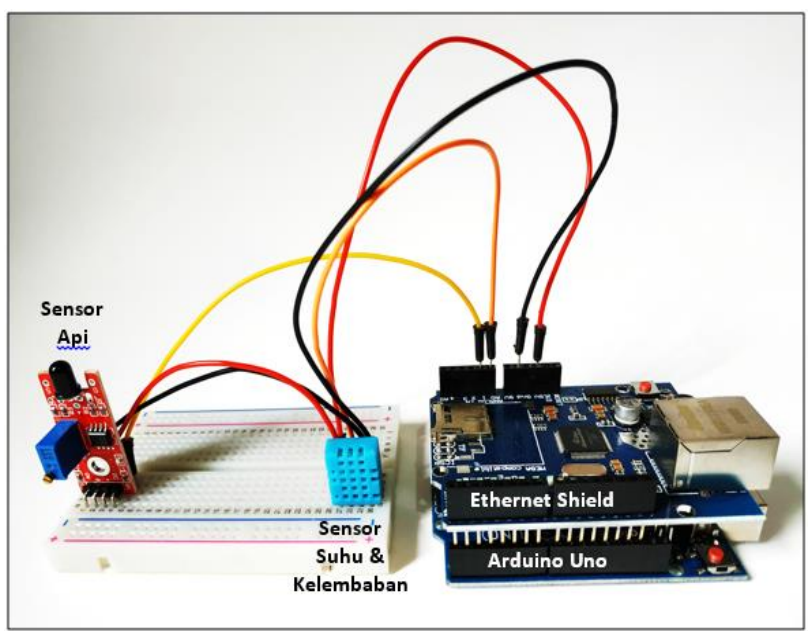

\section{Gambar 5 Rangkaian Perangkat Keras}

\subsection{Perancangan Perangkat Lunak (Software)}

Perangkat lunak yang dibutuhkan dalam membangun sistem peringatan dini bahaya kebakaran ini mencakup:

1. Perangkat lunak untuk mengoperasikan sistem mikrokontroler Arduino Uno.

Program atau perangkat lunak yang digunakan untuk mengoperasikan sistem mikrokontroler Arduino Uno disebut dengan sketsa. Sketsa yang merupakan program Arduino tersebut ditulis menggunakan bantuan Arduino IDE (Integrated Development Environment). Sketsa yang digunakan untuk mengoperasikan sistem peringatan dini bahaya kebakaran dapat dilihat pada gambar 6. Program di dalam sketsa tersebut dijalankan berulang dalam durasi waktu per 10 (sepuluh) detik sehingga pengguna mendapatkan data mutakhir dari kondisi sekitar tempat modul sensor diletakkan. 


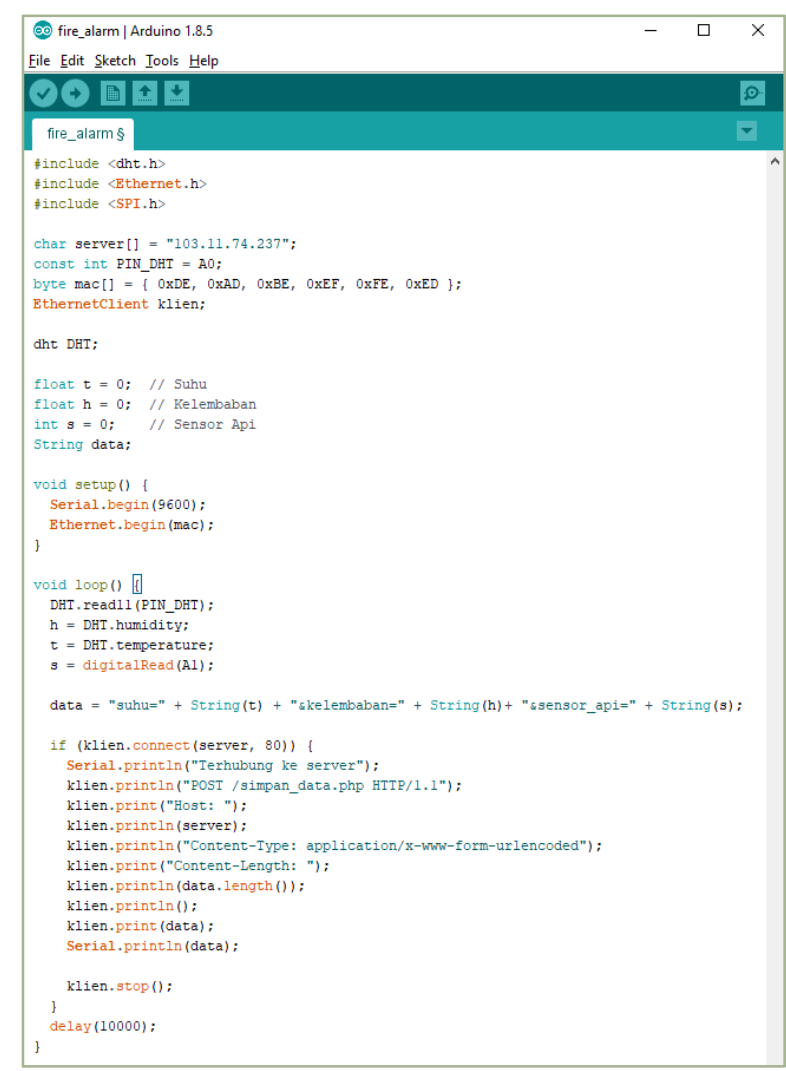

Gambar 6 Program Arduino (Sketsa)

2. Perangkat lunak untuk menyimpan data pada database server Data yang didapatkan dari hasil pengukuran modul sensor api dan suhu/kelembaban harus disimpan dalam sebuah database server terlebih dahulu untuk kemudian dapat diambil oleh aplikasi Android dan disajikan pada pengguna. Sistem manajemen database yang digunakan dalam penelitian ini adalah MySQL. Adapun struktur tabel database sistem peringatan dini bahaya kebakaran dapat dilihat pada gambar 7. Field yang digunakan antara lain ID_DATA (auto increment), WAKTU, SUHU, KELEMBABAN, dan SENSOR_API. Field SENSOR_API hanya akan menyimpan angka 1 (satu) dan 0 (nol), dimana angka 0 (nol) menandakan bahwa sensor sedang tidak mendeteksi adanya api, sedangkan angka 1 (satu) menandakan adanya api disekitar sensor.

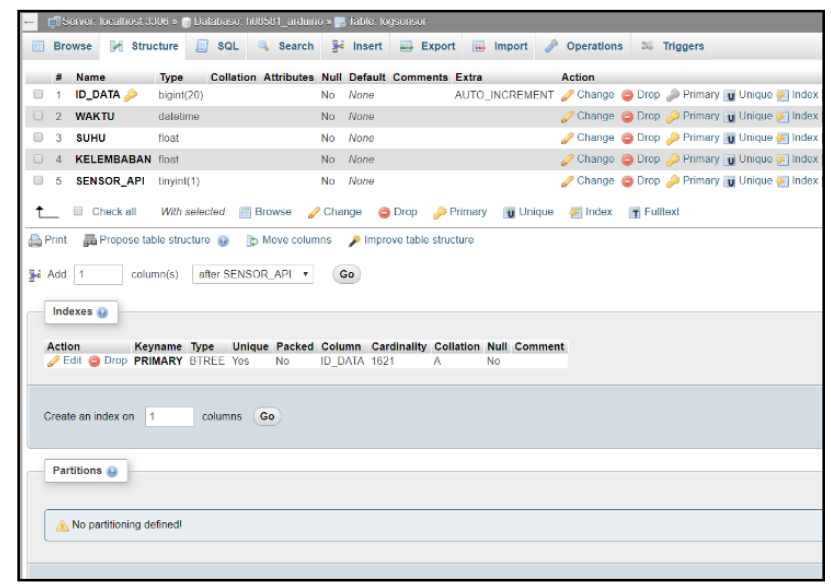

Gambar 7 Struktur Tabel Database
3. Perangkat lunak untuk menampilkan data/informasi pada perangkat Android

Aplikasi android dalam sistem peringatan dini bahaya kebakaran digunakan untuk mengambil data yang ada di database server kemudian disajikan dalam bentuk data dan informasi kepada pengguna. Alat bantu perancangan aplikasi android dalam penelitian ini adalah menggunakan MIT App Inventor 2. Desain antarmuka aplikasi android sistem peringatan dini bahaya kebakaran dapat dilihat pada gambar 8. Data yang ditampilkan pada aplikasi android berupa data suhu dalam derajat Celcius, data kelembaban dalam persen, dan data deteksi sensor api dalam angka boolean 1 (satu) atau 0 (nol). Data sensor api digunakan untuk memicu dibunyikannya suara alarm peringatan tanda bahaya kebakaran jika angka yang diterima dari database server berupa angka 1 (satu). Alarm akan terus berbunyi walaupun jika sesaat kemudian data sensor api kembali menjadi angka 0 (nol), hal ini dibuat atas dasar prinsip kehati-hatian. Alarm akan berhenti ketika tombol STOP ALARM ! disentuh dengan asumsi bahwa pengguna selanjutnya dapat memonitor perubahan suhu dan kelembaban untuk memastikan lebih lanjut bahwa memang telah terjadi kebakaran.

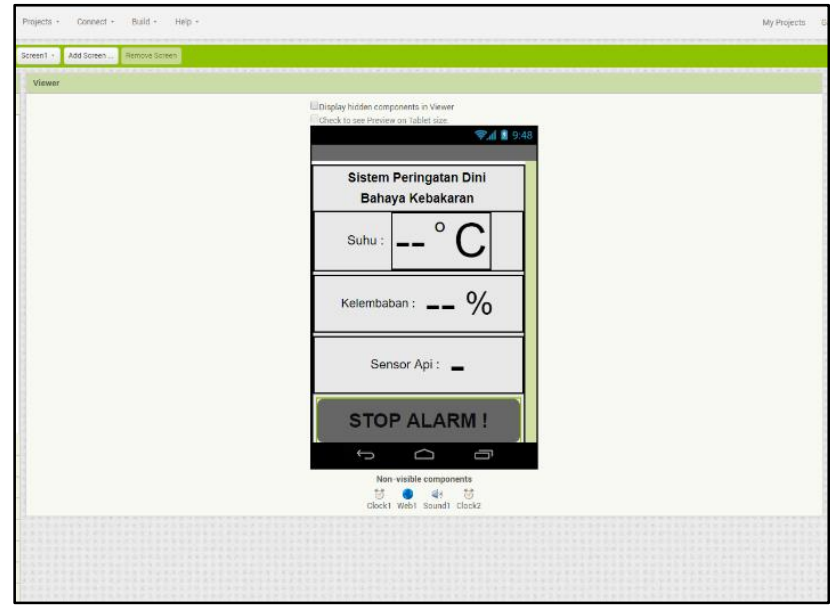

Gambar 8 Desain Antarmuka Aplikasi Android

\subsection{Pengujian Sistem}

Proses pengujian terhadap sistem peringatan dini bahaya kebakaran yang telah dibuat dibagi menjadi beberapa tahap, yaitu: tahap pertama adalah pengujian terhadap proses pengukuran besaran suhu, kelembaban, dan deteksi api oleh integrasi rangkaian perangkat keras arduino, tahap kedua adalah pengujian terhadap proses penyimpanan data pada database server, dan tahap ketiga adalah pengujian terhadap proses menampilkan data dan informasi menggunakan aplikasi android.

Pengujian tahap pertama adalah pengujian terhadap proses pengukuran besaran suhu, kelembaban, dan deteksi api oleh integrasi rangkaian perangkat keras arduino. Sebagai sumber api di dalam pengujian ini digunakan api dari sebuah lilin yang kemudian diatur jaraknya terhadap posisi sensor api. Hasil dari pengujian ini dapat dilihat melalui tampilan Serial Monitor pada IDE Arduino sebagaimana yang terlihat pada gambar 9. Dari hasil pengujian didapatkan jarak maksimal antara api dan sensor 
sehingga terdeteksi adanya api oleh sensor adalah lebih kurang 2 meter.

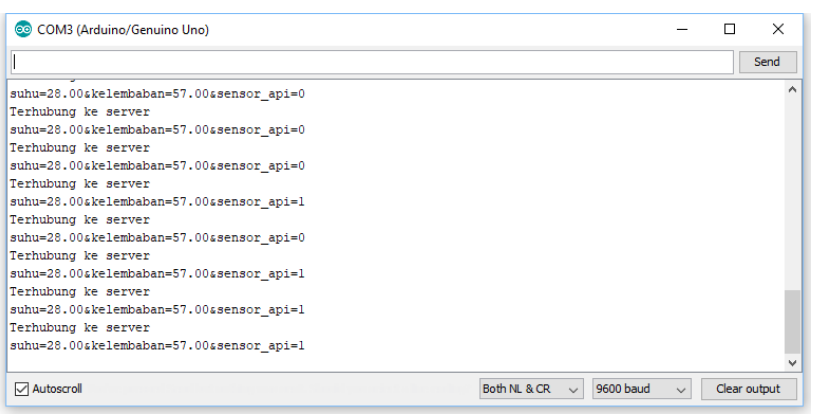

Gambar 9 Keluaran Serial Monitor Arduino IDE

Pengujian tahap kedua adalah pengujian terhadap proses penyimpanan data pada database server. Data suhu, kelembaban, dan deteksi api dari perangkat arduino dapat tersimpan dengan baik pada tabel database server sebagaimana terlihat pada gambar 10. Hasil pengujian didapatkan bahwa tabel database terupdate per 10 detik sesuai dengan program yang dibuat pada sketsa Arduino.

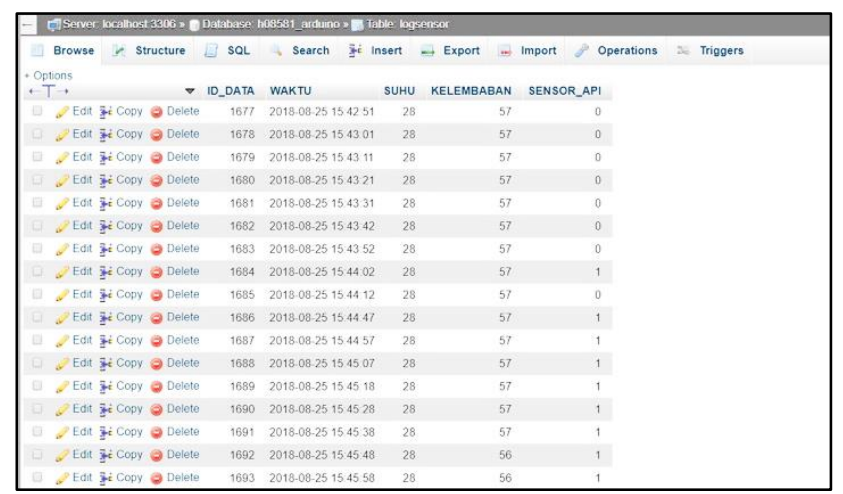

Gambar 10 Tabel MySQL Database

Pengujian tahap ketiga adalah pengujian terhadap proses menampilkan data dan informasi menggunakan aplikasi android. Perangkat keras mobile yang digunakan dalam pengujian ini adalah smartphone dengan prosesor Snapdragon 636 Octa-Core 1,8 GHz Kryo 260, RAM 3 GB, dan sistem operasi Android Oreo 8.1 .

Hasil pengujian berupa tampilan aplikasi android dapat dilihat pada gambar 11 dan gambar 12. Pada gambar 11 tampak hasil screen capture aplikasi ketika sumber api belum terdeteksi dan alarm tanda peringatan bahaya kebakaran belum aktif. Sedangkan pada gambar 11 tampak hasil screen capture aplikasi ketika sumber api telah terdeteksi dan alarm tanda peringatan bahaya kebakaran telah aktif. Tombol STOP ALARM ! hanya aktif ketika alarm peringatan bahaya kebakaran telah aktif. Hasil pengujian didapatkan bahwa data pada tampilan aplikasi terupdate per 10 detik sesuai dengan program yang dibuat menggunakan MIT App Inventor.

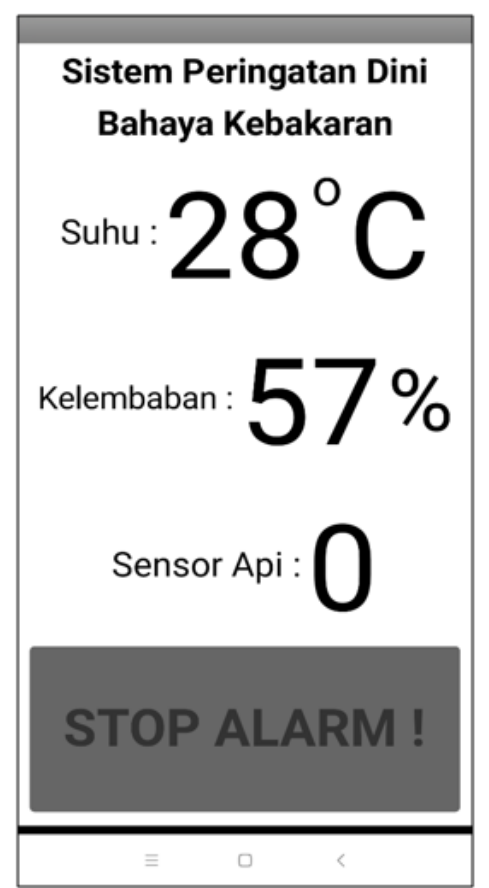

Gambar 11 Tampilan aplikasi Android sebelum alarm aktif

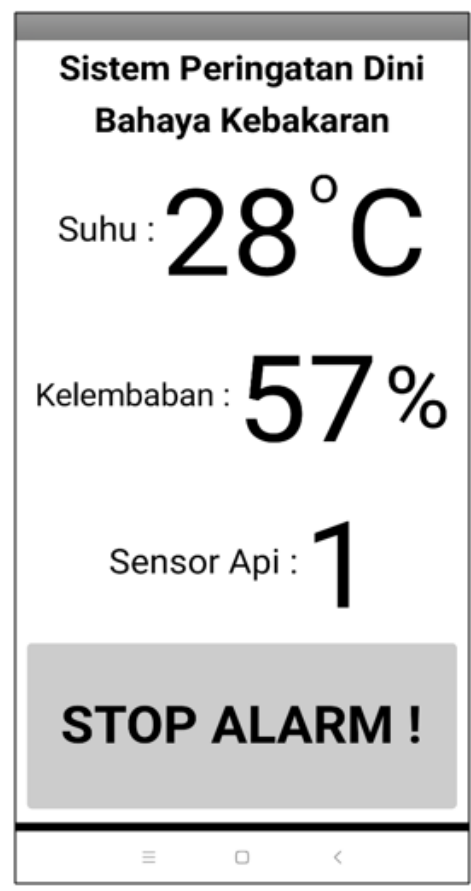

Gambar 12 Tampilan aplikasi Android setelah alarm aktif

\section{KESIMPULAN DAN SARAN}

\subsection{Kesimpulan}

Sistem peringatan dini bahaya kebakaran yang dibuat terdiri dari 3 (tiga) sub sistem yaitu yang pertama adalah integrasi perangkat keras sistem mikrokontroler Arduino Uno R3 ATmega328, modul sensor api KY-026, sensor suhu dan kelembaban DHT-11, serta modul Ethernet W5100. Sub sistem yang kedua adalah 
database server menggunakan MySQL. Sub sistem yang ketiga adalah aplikasi perangkat mobile Android yang dibuat menggunakan MIT App Inventor. Proses pengujian dibagi menjadi 3 (tiga) tahap yaitu yang pertama adalah pengujian terhadap integrasi perangkat keras Arduino. Hasil pengujian didapatkan bahwa sensor dapat mendeteksi adanya api ketika api tersebut berada dalam jarak radius lebih kurang 2 meter. Tahap kedua adalah pengujian terhadap kemampuan database server menyimpan data. Hasil pengujian didapatkan bahwa tabel database ter-update per 10 detik sesuai dengan program yang dibuat pada sketsa Arduino. Tahap ketiga adalah pengujian terhadap kemampuan aplikasi Android menampilkan data. Hasil pengujian didapatkan bahwa data pada tampilan aplikasi terupdate per 10 detik sesuai dengan program yang dibuat menggunakan MIT App Inventor.

\subsection{Saran}

Beberapa hal yang dapat menjadi pengembangan lebih lanjut terhadap hasil penelitian ini antara lain dapat difokuskan pada penggunaan sistem mikrokontroler dengan dimensi ukuran yang lebih kecil dari board Arduino Uno dan penggunaan jalur komunikasi nirkabel sehingga dapat meningkatkan fleksibilitas penempatan perangkat sistem peringatan dini bahaya kebakaran ini khususnya di tempat-tempat yang sulit dijangkau menggunakan kabel jaringan komputer.

\section{DAFTAR PUSTAKA}

[1] R. N. Kulkarni, Archana N., Charu Jain, Geetha N., Sangeeta B. 2017. Design and Implementation of IoT Based Home Automation. International Journal of Computer Trends and Technology (IJCTT). Volume: 48. Number: 1. Pp. 11-14.

[2] Raheela Shahzadi, Javed Ferzund, Muhammad Tausif, Muhammad Asif Suryani. 2016. Internet of Things based Expert System for Smart Agriculture. International Journal of Advanced Computer Science and Applications (IJACSA), Volume: 7. Number: 9. Pp 341-350.

[3] Rajkumar Buyya, Amir Vahid Dastjerdi. 2016. Internet of Things: Principles and Paradigms. Morgan Kaufmann (an imprint of Elsevier). Cambridge.

[4] Ojaswini Vijay Duragkar, P. V. Gawande. 2016. Design and Implementation of Industrial Automation System by Using Internet of Things (IoT). International Research Journal of Engineering and Technology (IRJET). Volume: 03. Issue: 05. Pp. 2184-2188.

[5] Safaat, Nazarudin. 2011. Pemrograman Aplikasi Mobile Smartphone dan Tablet PC Berbasis Android. Penerbit Informatika. Bandung.

[6] Sugiyono. 2008. Metode Penelitian Kunatitatif Kualitatif dan Research \& Development. Alfabeta. Bandung.

\section{BIODATA PENULIS}

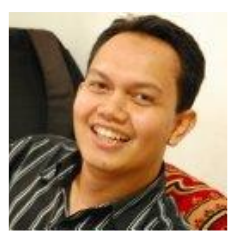

Nofiandri Setyasmara

Dosen pada Jurusan Desain Grafis, Politeknik Negeri Media Kreatif. 